\title{
Adiponectin receptor agonists inhibit leptin induced pSTAT3 and in vivo pancreatic tumor growth
}

\author{
Fanuel Messaggio ${ }^{1}$, Alisha M. Mendonsa ${ }^{2}$, Jason Castellanos ${ }^{3}$, Nagaraj S. \\ Nagathihalli $^{1}$, Lee Gorden ${ }^{3}$, Nipun B. Merchant ${ }^{1}$ and Michael N. VanSaun ${ }^{1}$ \\ ${ }^{1}$ Division of Surgical Oncology, Department of Surgery, Sylvester Comprehensive Cancer Center, University of Miami Miller \\ School of Medicine, Miami, Florida, USA \\ ${ }^{2}$ Department of Cancer Biology, Vanderbilt University Medical Center, Nashville, Tennessee, USA \\ ${ }^{3}$ Department of Surgery, Vanderbilt University Medical Center, Nashville, Tennessee, USA \\ Correspondence to: Michael N. VanSaun, email: mvansaun@med.miami.edu \\ Keywords: adiponectin, AdipoRon, pancreatic adenocarcinoma, adipokine, STAT3 \\ Received: February 17, 2017 \\ Accepted: July 18, 2017 \\ Published: August 03, 2017 \\ Copyright: Messaggio et al. This is an open-access article distributed under the terms of the Creative Commons Attribution License \\ 3.0 (CC BY 3.0), which permits unrestricted use, distribution, and reproduction in any medium, provided the original author and \\ source are credited.
}

\section{ABSTRACT}

Obesity is a significant risk factor for pancreatic cancer, harboring a chronic inflammatory condition characterized by dysregulation of the adipokines, leptin and adiponectin, that in turn alter oncogenic signaling pathways. We and others have shown that leptin promotes the proliferation and an invasive potential of pancreatic cancer cells through STAT3 mediated signaling. However, the role of adiponectin on the tumorigenicity of pancreatic cancer has not been elucidated. Adiponectin represents an important negative regulator of cytokines, which acts through two receptors, ADIPOR1 and ADIPOR2, to elicit pro-apoptotic, anti-inflammatory, and anti-angiogenic responses. We show that the level and expression of both adiponectin receptors are decreased in pancreatic tumors relative to normal pancreatic tissue. In vitro stimulation with adiponectin or a small molecule adiponectin receptor agonist, AdipoRon, increases apoptosis while inhibiting pancreatic cancer cell proliferation, colony formation, and anchorage independent growth. In addition, adiponectin receptor agonism inhibits leptin mediated STAT3 activation. In vivo, treatment of mice with AdipoRon inhibits orthotopic pancreatic tumor growth. These results demonstrate that adiponectin receptor activation is a key regulator of pancreatic cancer growth and AdipoRon provides a rational agent for the development of novel therapeutic strategies for pancreatic cancer.

\section{INTRODUCTION}

Pancreatic cancer ranks as the third leading cause of cancer related deaths and is projected to be the second by the year 2020. Therefore, improving our understanding of the biology of pancreatic ductal adenocarcinoma (PDAC) is of paramount importance $[1,2]$. Epidemiological studies have linked pancreatic cancer risk with multiple factors including age, smoking, alcohol consumption, chronic pancreatitis, and Type II diabetes [3, 4]. The increasing incidence of pancreatic cancer is also associated with a rising prevalence of obesity, a documented adverse health risk for diabetes and pancreatitis [5-8].
Adipokines are adipose derived cytokines that can affect many aspects of cancer; acting as inflammatory mediators, growth factors, and angiogenic factors [9, 10]. The influence of adipokines on the initiation and progression of pancreatic cancer remains largely unknown. The adipokines, leptin and adiponectin, generally act in an opposing manner; leptin contributes to a pro-tumorigenic phenotype while adiponectin acts in an anti-tumorigenic manner. Stimulation of cancer cells with leptin leads to increased aggressiveness and metastatic phenotypes [11-13]. Conversely, adiponectin has been shown to inhibit proliferation, migration and invasion of breast cancer, prostate cancer and hepatic stellate cells [14-17]. 
Signal transducer and activator of transcription 3 (STAT3) signaling appears to be a key regulator of adipokine mediated activity. Administration of leptin to pancreatic cancer cell lines activates STAT3 signaling [13], whereas adiponectin inhibits leptin induced phosphorylation of STAT3 in prostate, esophageal and hepatocellular carcinoma cells $[18,19]$.

Reports on adiponectin levels in pancreatic cancer patients have been conflicting, however, high serum levels of adiponectin have been correlated with a decreased risk for pancreatic cancer [20, 21]. Importantly, a downregulation of adiponectin receptors has been observed in hepatocellular carcinoma and colorectal cancer [22, 23]. Therefore gaining an understanding of the regulation of adiponectin may have the potential to provide insights into the initiation and maintenance of pancreatic cancer and provide opportunities for novel treatment options. We show that there is a reduction in adiponectin receptor levels in mouse and human pancreatic cancer tumors and cell lines relative to normal pancreas tissue and report that supplementation with adiponectin or the adiponectin receptor agonist, AdipoRon, suppresses leptininduced STAT3 signaling in vitro and reduces PDAC tumor growth in vivo. Our results suggest that adiponectin receptor agonism represents a key regulatory mechanism for pancreatic cancer with novel therapeutic potential.

\section{RESULTS}

\section{Adiponectin receptor levels are decreased in pancreatic tumors}

While the presence of both ADIPOR1 and ADIPOR2 has previously been reported in human PDAC tumor samples [24], the localization and the expression level of these receptors relative to normal tissue has not been investigated. Using a human tissue microarray of normal pancreas and PDAC samples, we identified ADIPOR1 and ADIPOR2 to be primarily localized to the normal acinar tissue. In human PDAC tumors, the level of both ADIPOR1 and ADIPOR2 receptors were significantly decreased relative to normal acinar tissue (Figure 1A). PDAC samples collected from a genetically engineered mouse (GEM), PKT (Ptfla $\left.{ }^{\text {cre/++}} ; \mathrm{Kras}^{G 12 \mathrm{D} /+} ; \mathrm{Tgfbr} 2^{\text {flfft}}\right)$, also showed a decrease of both ADIPOR1 and ADIPOR2 in tumor tissue compared to the adjacent normal acinar tissue (Figure 1B). High power images of pancreatic tissue costained for peanut agglutinin (PNA) and ADIPOR1 or ADIPOR2 confirmed their localization with acinar tissue (Supplementary Figure 1A, 1B).

We further characterized the mRNA expression of AdipoR1 and AdipoR2 in human and murine pancreatic tumor tissue as well as PDAC cell lines relative to normal pancreas utilizing quantitative PCR analysis. Expression levels of AdipoR1 and AdipoR2 were decreased in human PDAC and in cell lines, Panc1 and MiaPaca2, compared to normal human pancreatic tissue (Figure 1C). Expression levels of AdipoR1 and AdipoR2 were also decreased in murine pancreatic cancer samples and in cell lines Panc02, P-4313, and K-8484 when compared to normal murine pancreatic tissue (Figure 1D). Adiponectin itself has not been reported to be expressed by pancreatic cancer cells at significant amounts. Therefore, we characterized the expression of adiponectin from cancer cells and pancreatic tissues using qRT-PCR. Pancreatic cancer cell lines did not express detectable levels of adiponectin in comparison to the robust expression in differentiated 3T3-L1 cells or peripheral adipose tissue (Figure 1E). We were able to detect expression of adiponectin in two of four samples of normal pancreas, yet expression was not detected from murine PDAC lysates (Figure 1E).

\section{Full length adiponectin inhibits proliferation of pancreatic cancer cells}

Adiponectin is secreted as a full length monomeric protein that can either aggregate into multimeric high molecular weight (HMW) clusters or be cleaved to generate globular ligands [25, 26]. ADIPOR1 preferentially responds to the globular form of adiponectin while ADIPOR2 responds to the full length monomeric and HMW forms [27]. Total levels of adiponectin in lean mice averaged $8.77 \mu \mathrm{g} / \mathrm{mL}$ (Supplementary Figure 3C). Of note, the globular form of adiponectin circulates at low abundance in human plasma as compared to full length adiponectin [28]. In order to determine the effect of adiponectin on the proliferation of pancreatic cancer cells, we exposed murine and human pancreatic cancer cells to either globular adiponectin, gADN $(1 \mu \mathrm{g} / \mathrm{mL})$ or full-length recombinant adiponectin, fADN $(10 \mu \mathrm{g} / \mathrm{mL})$. The globular form of adiponectin had no effect on cell proliferation, while the full length form of adiponectin significantly inhibited proliferation of the Panc1, MiaPaca2, and Panc02 cells (Figure 2A).

\section{AdipoRon, an adiponectin agonist, inhibits pancreatic cancer cell growth in vitro}

Recently, AdipoRon, a small molecule agonist of both adiponectin receptors ADIPOR1 and ADIPOR2, was shown to reduce diabetic symptoms in a genetically obese mouse model [29]. An effect not observed in double-knockout AdipoR1/AdipoR2 mice. In order to determine if AdipoRon could be used to treat PDAC, we administered AdipoRon to pancreatic cancer cells and assessed them for viability. The number of proliferating cells and the number of apoptotic cells were each quantified after AdipoRon treatment in mouse Panc02, P-4313 (obtained from GEM; Kras ${ }^{\mathrm{G} 12 \mathrm{D} /+}, \mathrm{Pdx}^{1 \mathrm{cre} /+}$ ) and K-8484 (obtained from GEM; $\mathrm{Kras}^{\mathrm{G} 12 \mathrm{D} /+}$, p53 $3^{\mathrm{R} 172 \mathrm{H} /+}$, $\mathrm{Pdx}^{\mathrm{cre} /+}$ ) cell lines as well as human Panc1 and MiaPaca 2 cell lines. AdipoRon administration to PDAC 
A
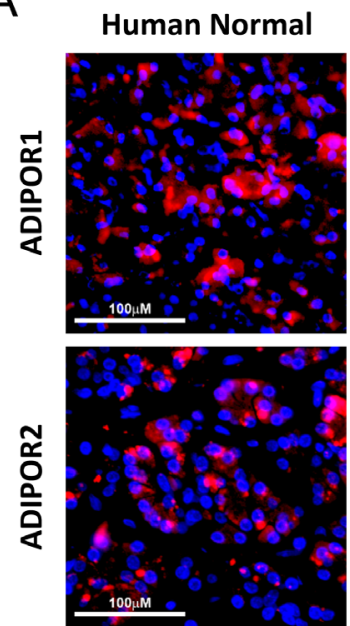

B
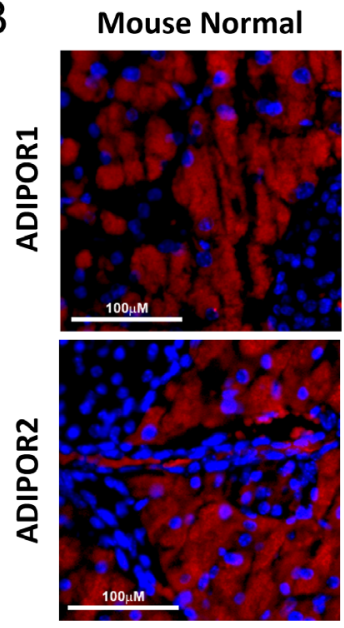

$E$

Human Cells

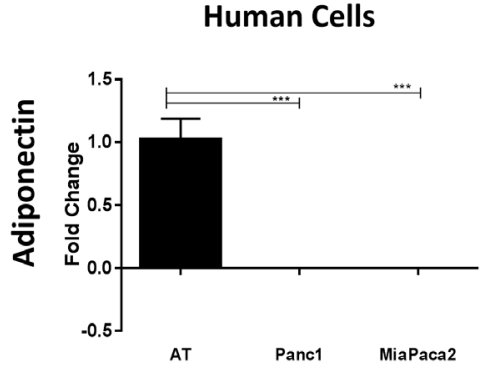

Human PDAC
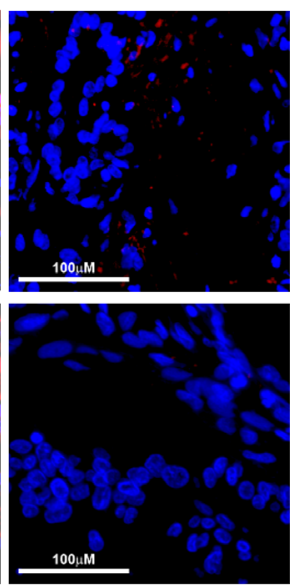

Mouse PDAC
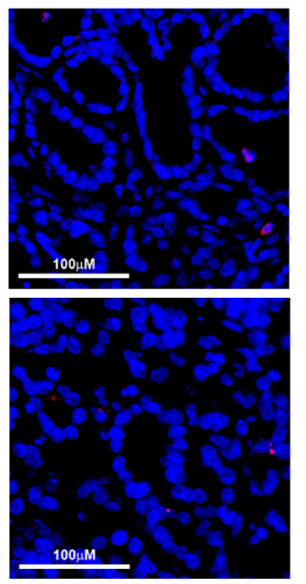
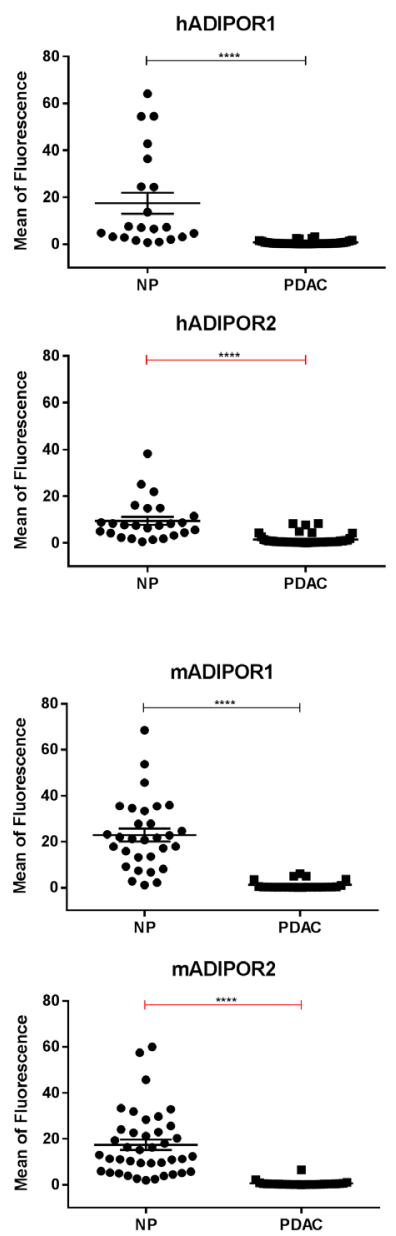

C
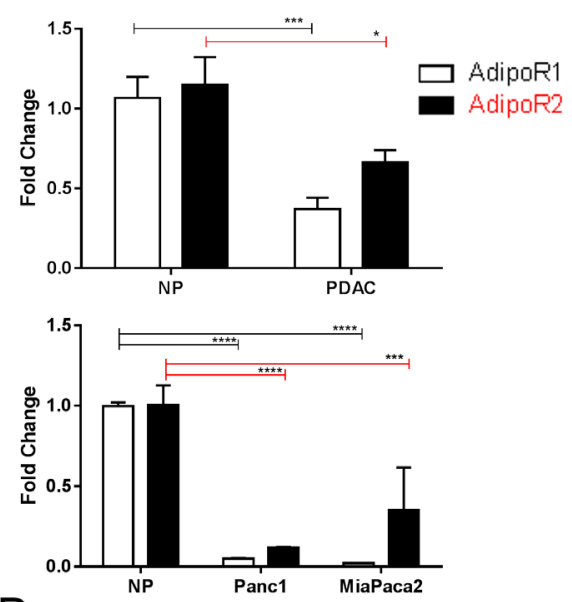

D
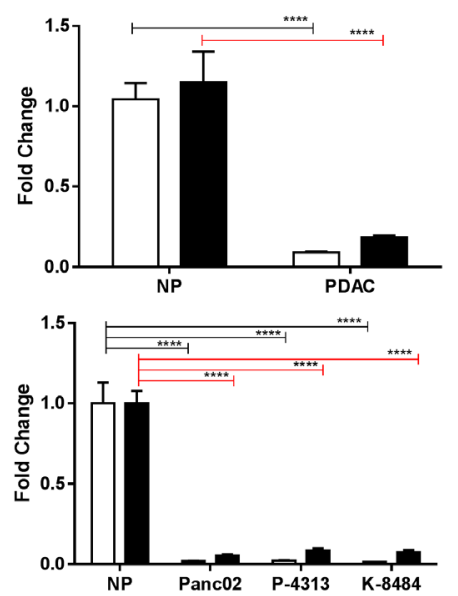

Mouse Cells

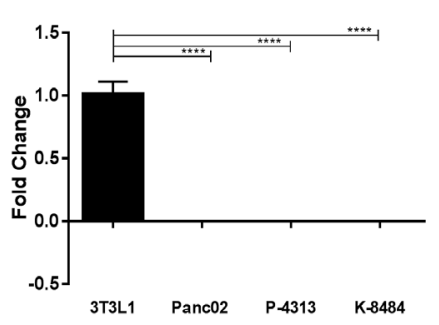

Mouse Tissue

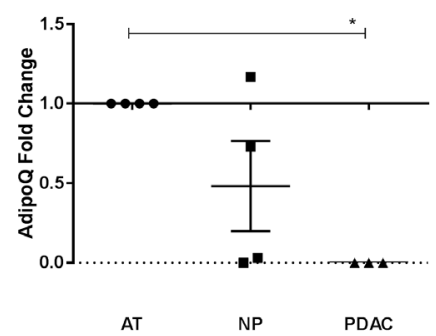

Figure 1: Adiponectin receptor levels are reduced in pancreatic cancer. Human and murine normal and pancreatic cancer samples were immunostained for ADIPOR1 and ADIPOR2. (A) strong staining is present in the acinar tissue of human normal samples for both receptors but is decreased in the human pancreatic tumor samples. (B) murine pancreatic cancer tissue samples from PKT mice demonstrate a high level of staining in the adjacent acinar tissue and a reduced staining in the dysplastic pancreatic tumor. Graphs represent quantitative analysis of mean fluorescence from single channel images. Scale bar is $100 \mu \mathrm{m}$. (C-D) quantitative real time PCR analysis was used to determine the relative expression of AdipoR1 (white bars) and AdipoR2 (black bars) in human and murine pancreatic tumor samples (PDAC) as well as in pancreatic cancer cell lines, relative to the level expressed in the normal pancreas (NP) tissue. (E) quantitative real time PCR analysis for adiponectin expression in human and mouse pancreatic cancer cell lines and mouse tissue, relative to human adipose tissue (AT), 3T3L1 cells differentiated to adipocytes (3T3L1) and mouse AT, respectively. Statistical analysis was performed separately for ADIPOR1 and ADIPOR2 protein levels (unpaired t-test) as well as AdipoR1 and AdipoR2 expression (two-way Anova), or adiponectin expression (ordinary one-way Anova) $(* \mathrm{P} \leq 0.05, * * * \mathrm{P} \leq 0.001, * * * * \mathrm{P} \leq 0.0001)$. 
cells resulted in a significant, concentration-dependent reduction of cell proliferation (Figure 2B) as well as increased apoptosis (Figure 3).

To determine the effectiveness of prolonged exposure to AdipoRon, PDAC cells were plated at low density and treated with AdipoRon in a concentration dependent manner for 2 weeks, which resulted in an effective growth suppression of PDAC cell colonies when compared to DMSO control treated cells (Figure 4A, 4B). Furthermore, AdipoRon treatment caused a significant decrease in anchorage independent growth as measured by overall spheroid area and diameter of Panc1 and MiaPaca2 cells (Figure 5A, 5B). Collectively, these results demonstrate that the adiponectin receptor agonist, AdipoRon, inhibits PDAC tumorigenesis in vitro.

\section{AdipoRon inhibits leptin mediated STAT3 activation}

Upon receptor binding, adiponectin classically activates AMPK signaling through the APPL1 adaptor protein [30]. To determine the molecular mechanism of AdipoRon in PDAC cells, murine K-8484 and human Panc1 cells were treated with increasing concentrations of AdipoRon. Similar to adiponectin, AdipoRon activated pAMPK signaling (Figure 6A, 6B) and subsequently increased pACC (Supplementary Figure 2). Additionally, AdipoRon treatment of PDAC cells resulted in a decreased level of pSTAT3. We have previously shown that leptin activates STAT3 phosphorylation in PDAC cells [13]. We now show that AdipoRon inhibits leptin induced pSTAT3 activation in PDAC cells at both lean $(5 \mathrm{ng} / \mathrm{mL})$ and obese (70ng/mL) concentrations of leptin (Figure 6C, 6D).
A
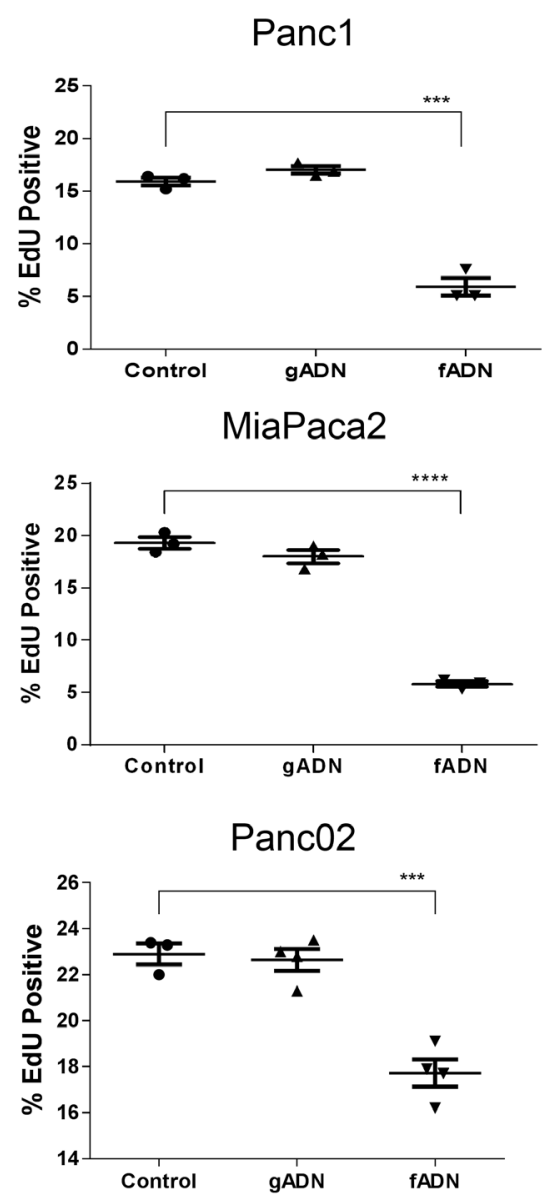

B
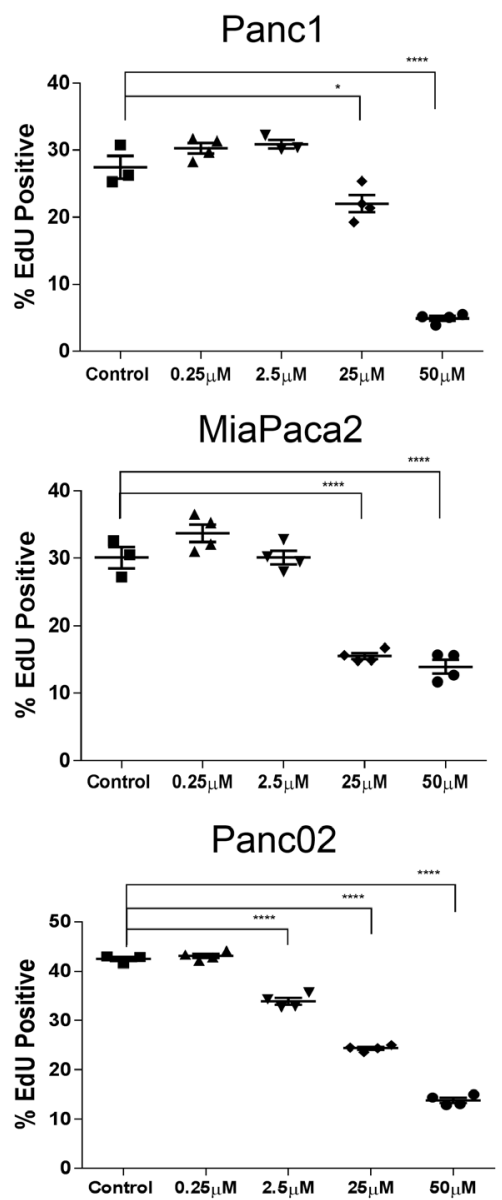

AdipoRon
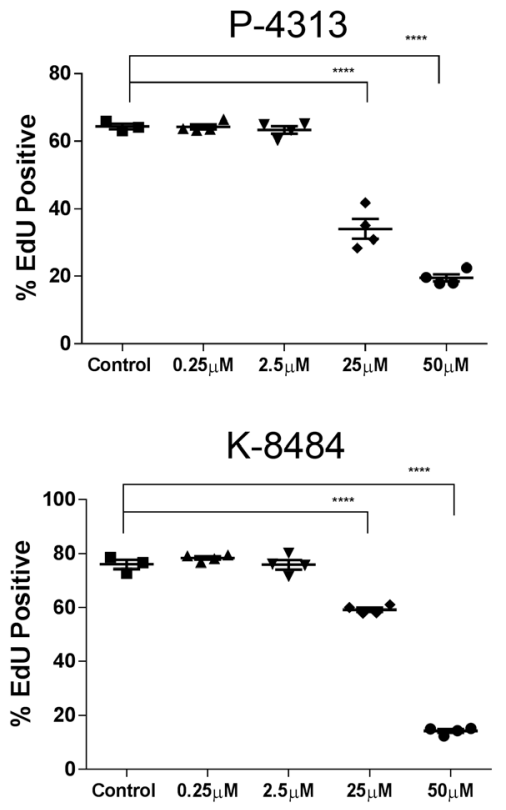

Figure 2: Adiponectin receptor agonists inhibit pancreatic cancer cell proliferation. (A) recombinant globular adiponectin $(\mathrm{gADN})$ at $1 \mu \mathrm{g} / \mathrm{mL}$ or full length adiponectin (fADN) at $10 \mu \mathrm{g} / \mathrm{mL}$ were incubated with human (Panc1 and MiaPaca2) and mouse (Panc02) pancreatic cancer cell lines, labeled with EdU and measured for active proliferation. DMSO was used as a control. Statistical analysis was performed using unpaired t-test $(* * * \mathrm{P} \leq 0.001, * * * * \mathrm{P} \leq 0.0001)$. (B) human (Panc1 and MiaPaca2) and mouse PDAC cells (Panc02, P-4313 and K-8484) were treated with increasing concentration of AdipoRon for $48 \mathrm{~h}$ before measuring proliferation via EdU, which showed dosedependent inhibition for each PDAC cell line. Statistical significance was determined using ordinary one-way Anova $(* \mathrm{P} \leq 0.05, * * * * \mathrm{P} \leq$ 0.0001). 


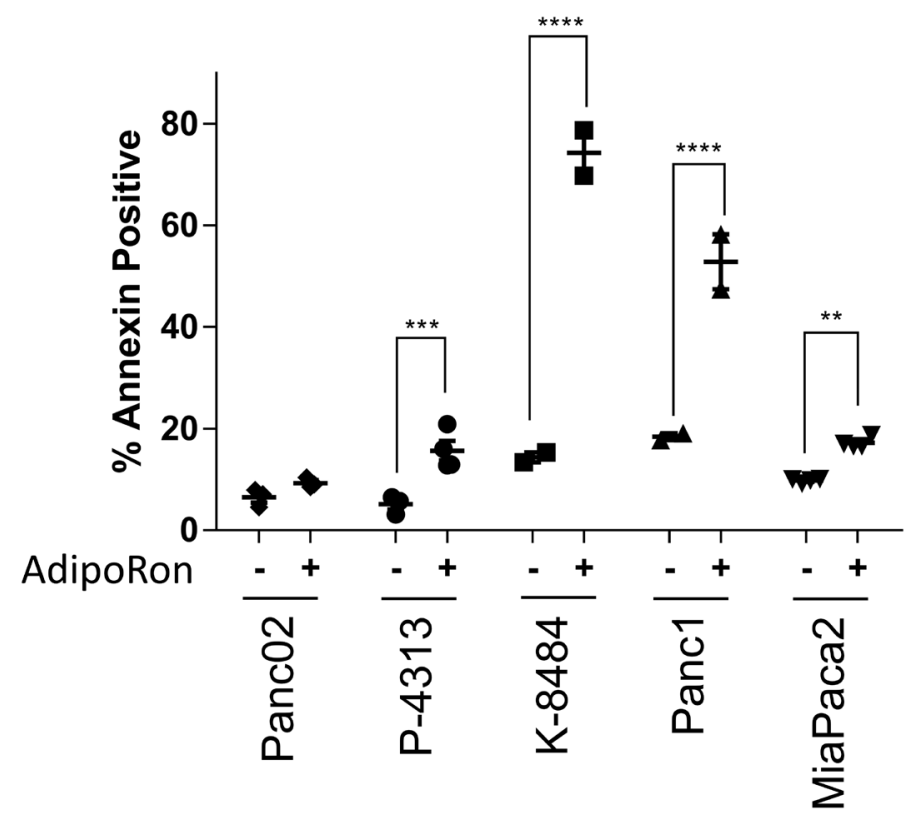

Figure 3: Adiponectin receptor agonist AdipoRon promotes pancreatic cancer cell apoptosis. Annexin V staining was used to evaluate the change in percentage of apoptotic cells by comparing 50 $\mu \mathrm{M}$ AdipoRon treatment (+) versus control (-) in multiple PDAC cell lines. Statistical significance was determined using ordinary one-way Anova test $(* * \mathrm{P} \leq 0.01, * * * \mathrm{P} \leq 0.001, * * * * \mathrm{P} \leq 0.0001)$.

A
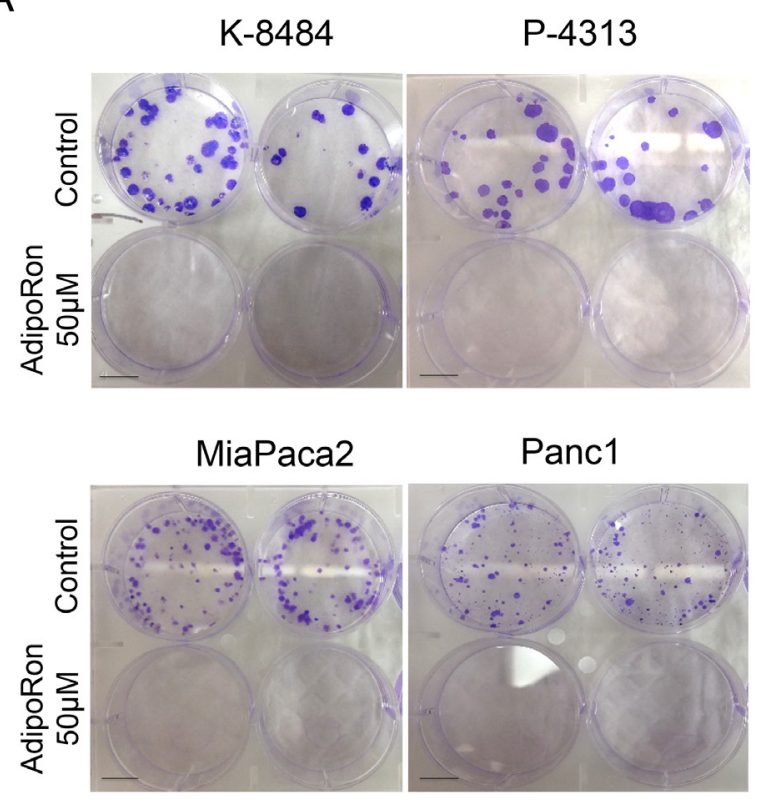

B

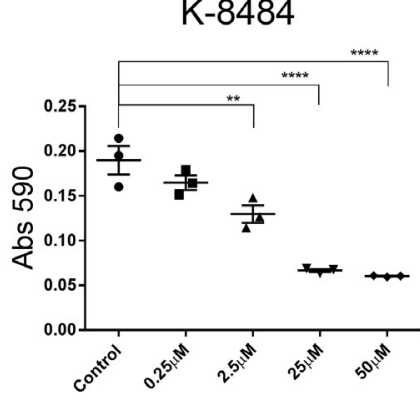

MiaPaca2

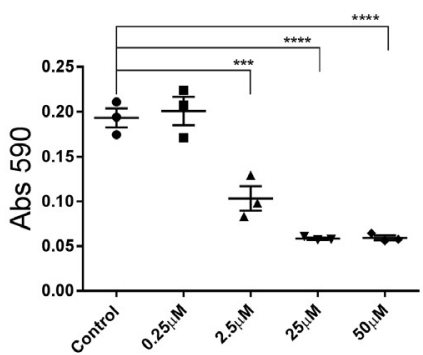

P-4313

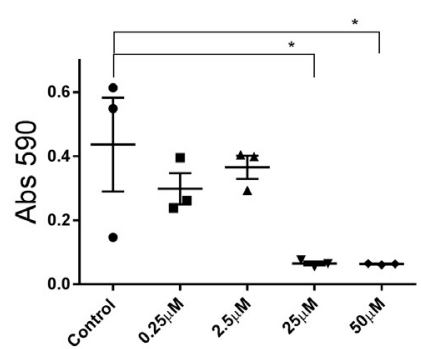

Panc1

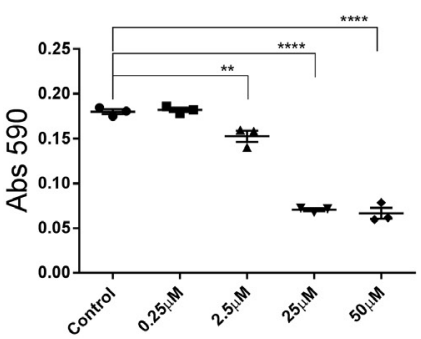

Figure 4: AdipoRon inhibits colony formation of pancreatic cancer cells. PDAC cell lines were treated with an increasing concentration of AdipoRon for 2 weeks. (A) representative images show a drastic decrease in colony number and size after AdipoRon treatment compared to control. (B) crystal violet staining was performed and quantification of stain was determined by reading absorbance at $590 \mathrm{~nm}$. Colony formation was decreased for both murine and human pancreatic cancer cell lines. Statistical analysis was performed using ordinary one-way Anova test $\left(* \mathrm{P} \leq 0.05,{ }^{* *} \mathrm{P} \leq 0.01, * * * \mathrm{P} \leq 0.001,{ }^{* * * *} \mathrm{P} \leq 0.0001\right)$. 
A
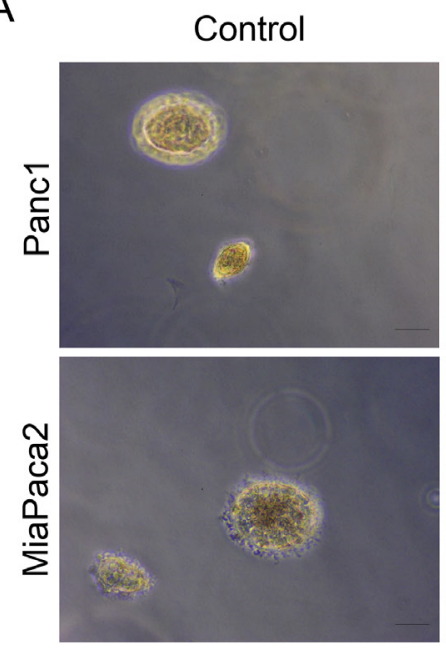

AdipoRon
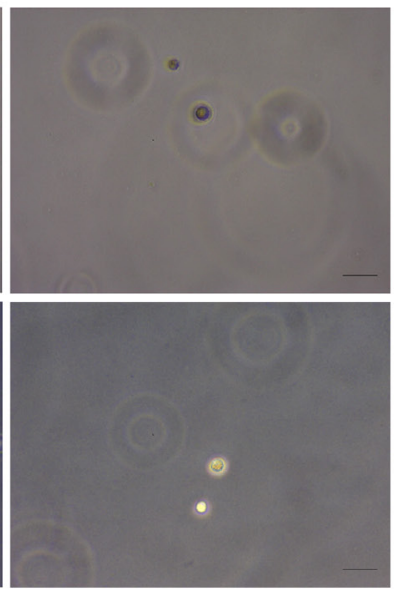

B

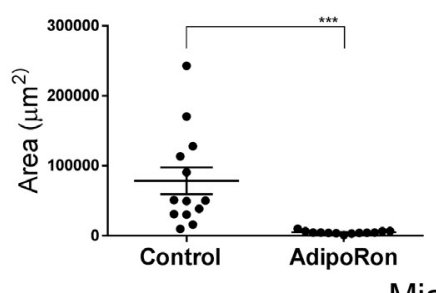

Panc1
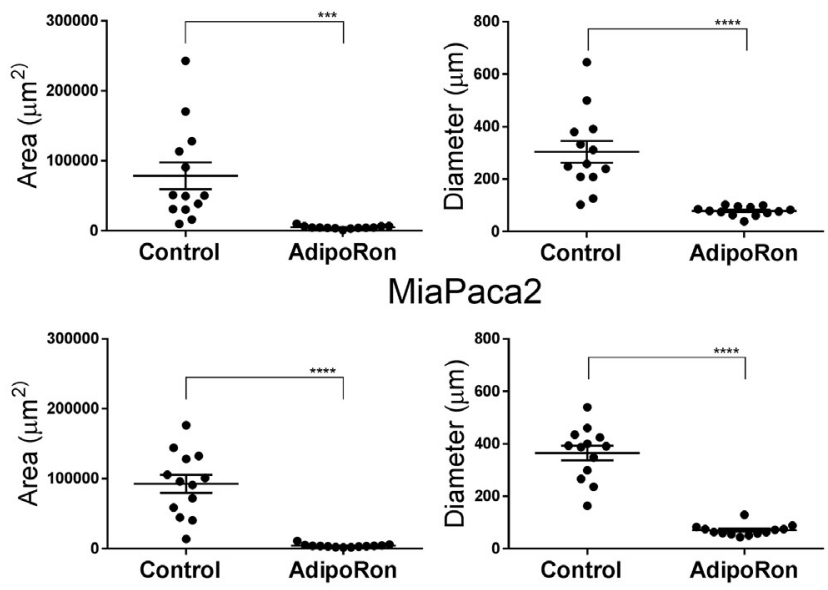

Figure 5: AdipoRon inhibits anchorage independent growth. PDAC cell lines were seeded in soft agar and treated with an

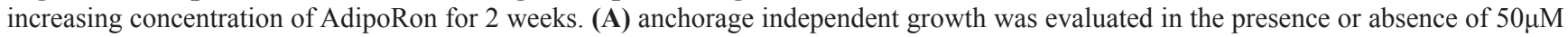
AdipoRon. (B) quantitative assessment of spheroid area as well as spheroid diameter were both decreased with AdipoRon treatment compared to control. Statistical analysis was performed using ordinary one-way Anova $\left(* * * \mathrm{P} \leq 0.001,{ }^{* * * *} \mathrm{P} \leq 0.0001\right)$.

A

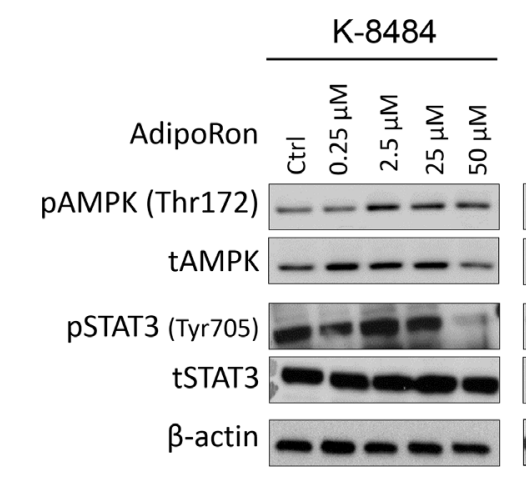

C
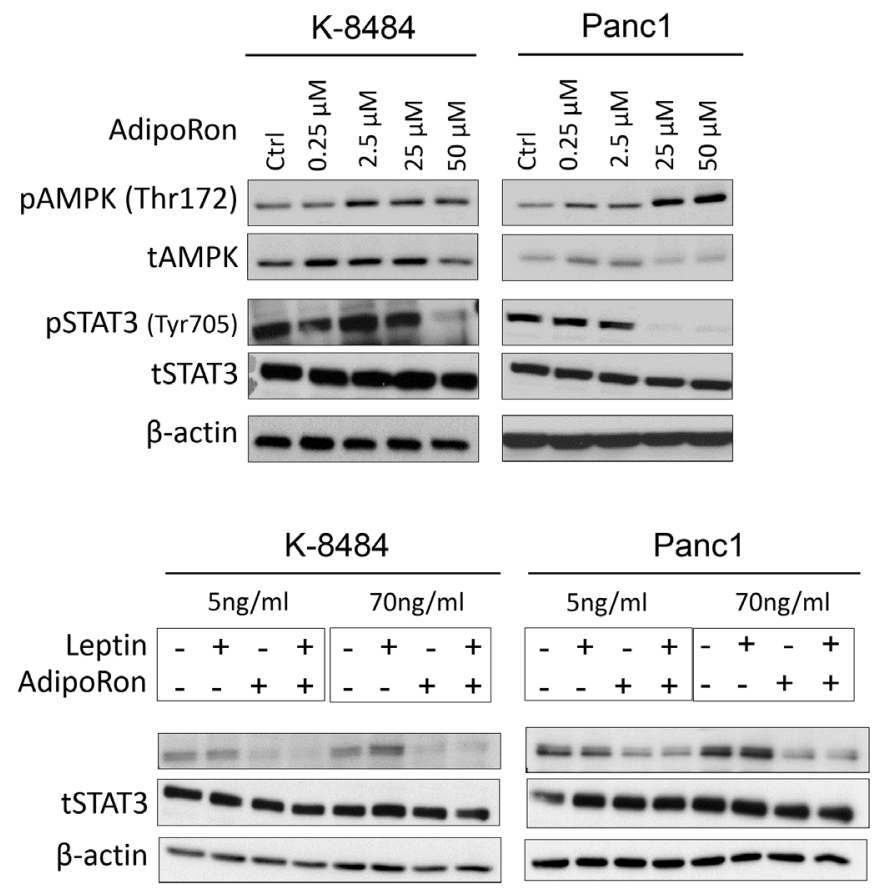

B
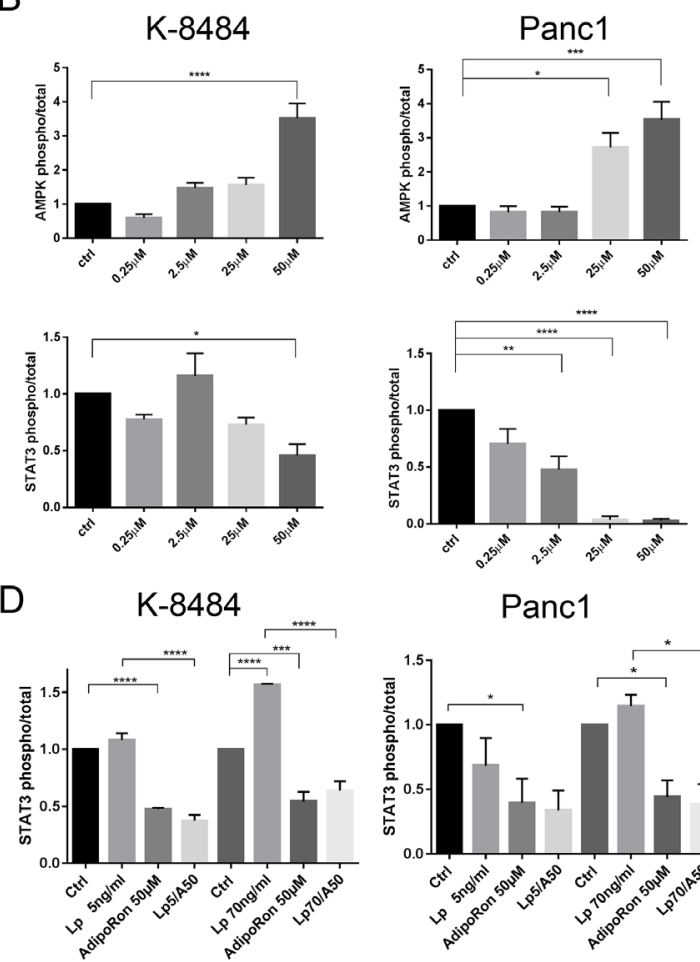

Panc1

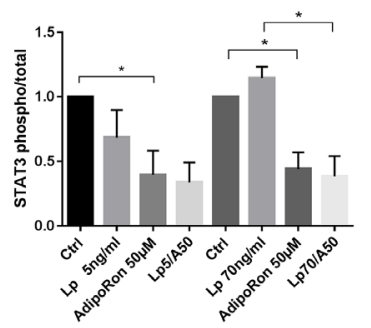

Figure 6: AdipoRon inhibits cytokine-induced pSTAT3. (A) qualitative representation of mouse K-8484 and human Panc1 PDAC cells starved overnight and then treated with increasing concentrations of AdipoRon for $12 \mathrm{~h}$. At the endpoint cells were lysed and probed with either pAMPK, tAMPK, pSTAT3, or tSTAT3 antibody. (B) correspondent relative quantitation of triplicate experiments. (C) AdipoRon inhibits Leptin-induced STAT3 activation. K-8484 and Panc1 PDAC cell lines were starved overnight and then treated with Leptin at lean concentration of $5 \mathrm{ng} / \mathrm{ml}$ or an obese concentration of $70 \mathrm{ng} / \mathrm{ml}$ alone or in combination with $50 \mu \mathrm{M}$ AdipoRon for $12 \mathrm{~h}$. Western analysis demonstrated suppression of leptin-induced pSTAT3 in the presence of AdipoRon. (D) correspondent relative quantitation of triplicate experiments. $\beta$-actin levels are shown as a total loading control. Statistical analysis was performed using ordinary one-way Anova $(* \mathrm{P} \leq$ $\left.0.05, * * \mathrm{P} \leq 0.01 * * * \mathrm{P} \leq 0.001,{ }^{* * * *} \mathrm{P} \leq 0.0001\right)$. 
These results confirm that during concurrent activation, adiponectin signaling counters the mitogenic effects of leptin in PDAC cells.

\section{AdipoRon inhibits pancreatic tumor growth in vivo}

We then sought to determine the effects of AdipoRon on pancreatic tumor growth in vivo. Murine

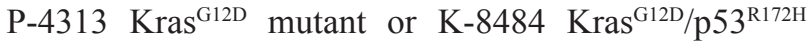
pancreatic cells were injected into the pancreas of naïve

A

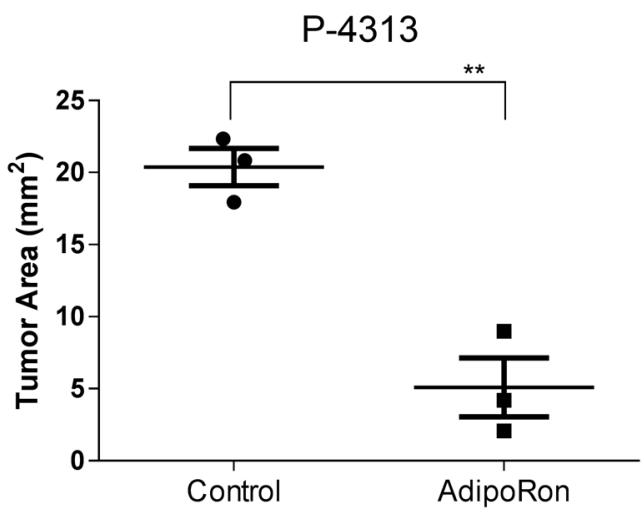

B

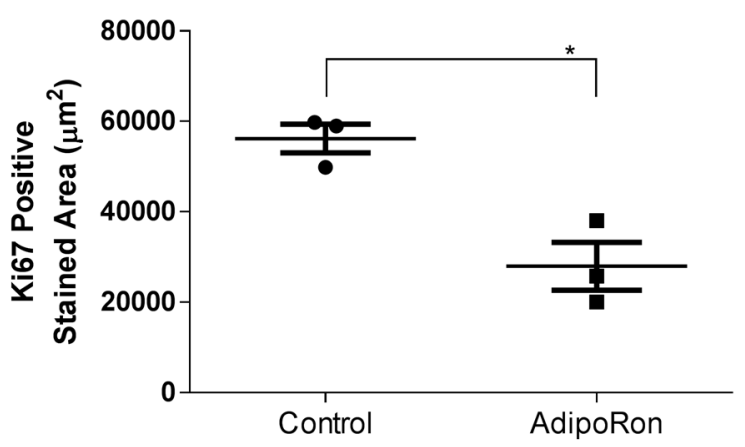

C

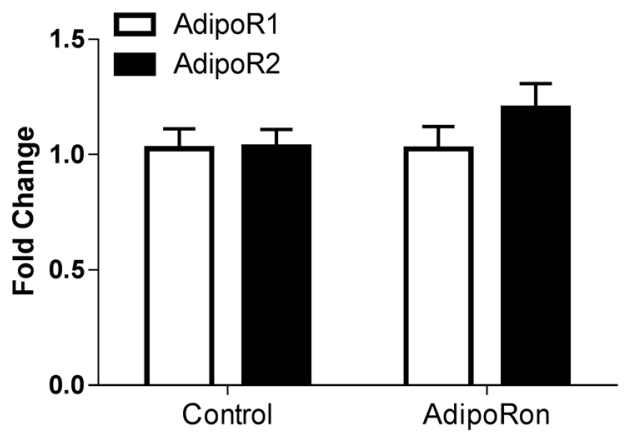

mice and allowed to establish for two weeks before treating the mice with either vehicle or AdipoRon $(5 \mathrm{mg}$ / $\mathrm{kg}$ /day). AdipoRon treated mice showed a significant reduction in the growth of orthotopic pancreatic tumors compared to vehicle treated tumors (Figure 7A). The level of tumor proliferation, as measured by Ki67 positive cells per tumor area, was significantly reduced in AdipoRon treated mice compared to vehicle treatment (Figure 7B). In a comparative model, syngeneic Panc02 (derived from a carcinogen induced tumor) or P-4313 pancreatic cancer cells were injected orthotopically into adiponectin deficient
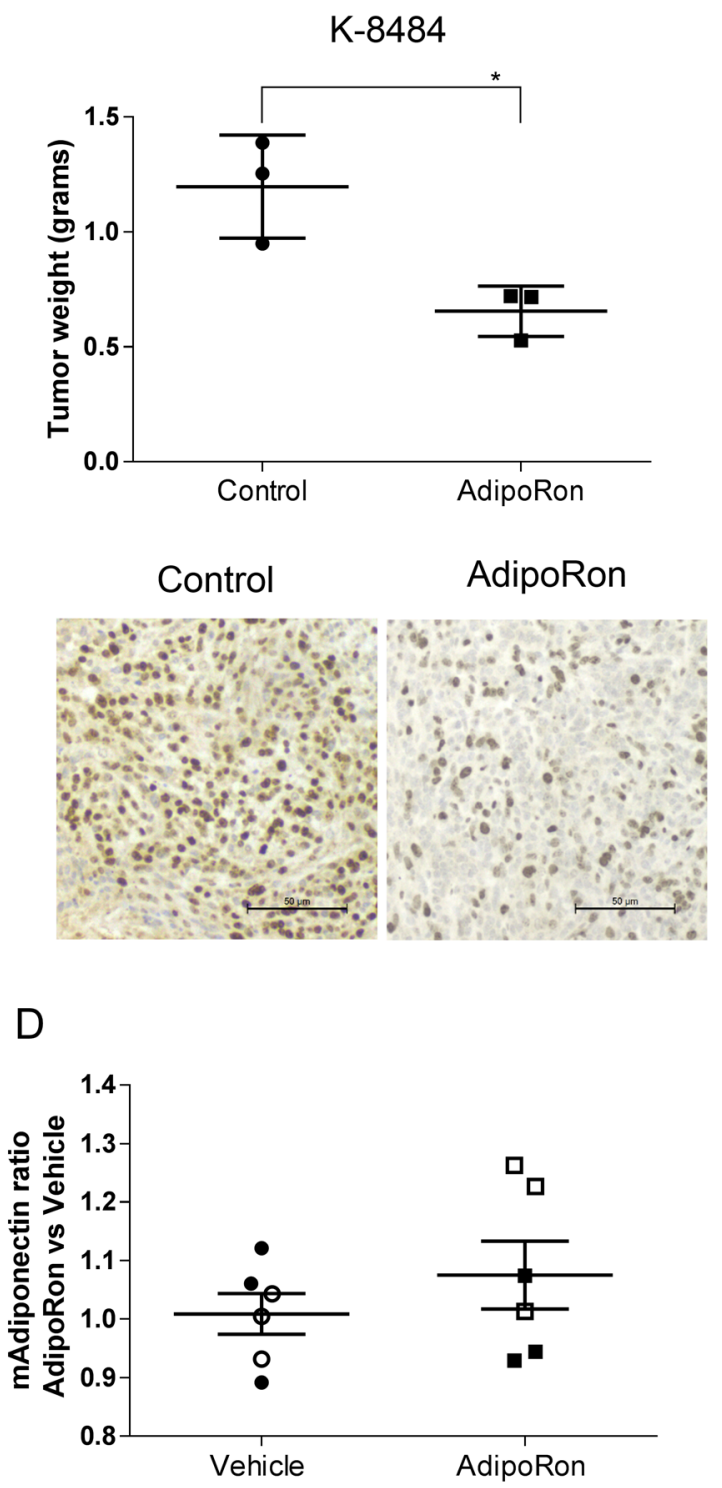

Figure 7: AdipoRon inhibits orthotopic pancreatic tumor growth and tumor proliferation in vivo. Murine P-4313 and K-8484 cancer cells were orthotopically injected into syngeneic wildtype mice and allowed to grow for two weeks, after which mice were treated with vehicle or AdipoRon 5mg/kg/day for 2 weeks. (A) at endpoint, AdipoRon treated mice had a significantly reduced tumor size. (B) tumor proliferation measured by Ki67 positive tumor area per tumor section was significantly reduced after AdipoRon treatment. (C) no significant difference was detected in relative expression of AdipoR1 (white bars) and AdipoR2 (black bars) by quantitative real time PCR analysis between control and AdipoRon treated tumors. (D) ELISA analysis showed no significant difference in circulating serum adiponectin levels between the two groups of mice. (P-4313 filled symbols and K-8484 open symbols). Statistical analysis was performed using unpaired t-test $(* \mathrm{P} \leq 0.05, * * \mathrm{P} \leq 0.01)$. 
mice. The absence of adiponectin resulted in an increased growth of Panc02 tumors, yet did not significantly affect the growth of P-4313 tumors when compared to respective tumors in wild-type mice (Supplementary Figure 3). These results further validate the role of adiponectin in inhibiting pancreatic tumor growth. ELISA based analysis of serum from adiponectin deficient mice (Supplementary Figure 3C) or conditioned media from murine PDAC cell lines (Supplementary Figure 3D) revealed undetectable levels of adiponectin in comparison to wildtype mice or differentiated 3T3-L1 adipocytes respectively.

\section{DISCUSSION}

Obesity is commonly associated with multiple forms of cancer including breast, colon, pancreas, prostate and uterine [31]. Serum levels of adipokines change greatly in obese individuals, resulting in decreased levels of adiponectin and increased levels of leptin [32-34]. The adipokines leptin and adiponectin are known to affect multiple aspects of cancer progression [35]. The overall objective of these studies was to understand pancreatic cancer growth in response to adiponectin or a small molecule adiponectin receptor agonist, AdipoRon. In this study we provide the first evidence that both adiponectin and AdipoRon inhibit pancreatic tumor growth and overcome leptin mediated mitogenic signaling.

Immunohistochemical analysis of human and murine PDAC tumors showed a downregulation of both adiponectin receptors, ADIPOR1 and ADIPOR2, in cancer compared to adjacent normal acinar tissue. In comparison, adiponectin receptors levels have also been shown to be significantly lower in human hepatocellular carcinoma [22], high-grade endometrial adenocarcinoma [36], and in colorectal cancer [37] when compared to adjacent nonneoplastic tissue. Furthermore, a lower expression of these receptors correlated with an increased risk of recurrence in hepatocellular carcinoma and poorly differentiated colorectal cancers [23].

To date, no studies have identified a mechanism for the regulation of adiponectin receptors in pancreatic cancer. Mutations in the adiponectin receptor have been reported, yet they are infrequent and it is likely that epigenetic changes in the adiponectin receptor promoter could be an important factor in PDAC. Obesity has been demonstrated to cause hypermethylation of the adiponectin [38] leading to subsequent suppression of adiponectin expression. Epigenetic analysis for adiponectin, AdipoR1, and AdipoR2 in PDAC will help to clarify the molecular mechanisms regulating expression in PDAC. We have found that although adiponectin receptors are expressed at low levels in PDAC, it is either sufficient enough to respond to increased levels of adiponectin/ AdipoRon or alternate receptors such as T-Cadherin may be compensating.
Previous studies have shown that adiponectin can inhibit the growth of a variety of cancer cells in culture $[15,17,39-41]$. We show that stimulation with full length adiponectin inhibited proliferation of pancreatic cancer cells in vitro at $10 \mu \mathrm{g} / \mathrm{mL}$, a concentration in the range of circulating blood levels in healthy patients. Furthermore, the small molecule agonist AdipoRon was also effective at inhibiting proliferation as well as inducing apoptosis in a panel of murine and human pancreatic cancer cell lines. AdipoRon may represent an economical pharmacological method to achieve super-physiological levels of adiponectin as a receptor agonist.

Recently, two reports preliminarily addressed pancreatic cancer growth in adiponectin deficient mice using variants of the murine Panc02 pancreatic cancer cell line with opposing results $[42,43]$. Kato, et al. showed that loss of adiponectin resulted in increased tumor size of orthotopically implanted PDAC tumors and decreased apoptosis [42]. In contrast, Huang, et al., showed decreased tumor growth and increased cleaved caspase-3 levels in flank injected PDAC tumors grown in adiponectin deficient mice [43]. The discrepancy of these results might be explained by microenvironmental factors related to the location of the implanted tumor. Similar to the Kato study, we found an increased growth of Panc02 tumors orthotopically implanted into adiponectin deficient mice. Interestingly, P-4313 cells did not demonstrate a growth benefit from loss of adiponectin. One possible difference in growth could be due to presence of mutant Kras in the P-4313 cells, as the Panc02 do not have a documented Kras mutation. Yet, determining whether mutant Kras is responsible for this growth effect would require additional validation. Importantly, neither study tested whether adiponectin treatment could be used to inhibit pancreatic tumors in vivo. Our studies demonstrate that AdipoRon significantly decreases the size and proliferation of P-4313 and K-8484 orthotopic pancreatic tumors in vivo.

Activation of STAT3 has been shown to occur frequently in cell lines and in human pancreatic cancers, which correlates with progression of disease [4447]. Our previous studies showed that leptin induced phosphorylation of STAT3 in PDAC cells [13]. Our group has also shown that activated STAT3 signaling is a key biomarker of resistance and confers a poor outcome in PDAC patients [44]. Here we show that adiponectin suppresses leptin induced STAT3 signaling in PDAC. Leptin induced STAT3 phosphorylation has also been shown to be inhibited by addition of adiponectin in hepatocellular cancer cells, which is associated with increased suppressor of cytokine signaling 3 (SOCS3) signaling, a negative regulator of STAT3 [41]. Inhibition of STAT3 signaling via adiponectin receptor activation provides a novel approach to inhibit PDAC tumor growth and progression and perhaps enhance therapeutic response to cytotoxic chemotherapy. 
In conclusion, we show that the two main receptors for adiponectin, ADIPOR1 and ADIPOR2, are downregulated in PDAC relative to normal pancreas. Restoration of healthy levels of adiponectin or supplementation with AdipoRon, even when adiponectin receptor expression is low, results in a generalized inhibition of cell proliferation of PDAC both in vitro and in vivo. We believe that reduction of adiponectin in obese individuals reduces the counteraction of stimulatory cytokines, such as leptin leading to a more severe phenotype. Our results are the first to demonstrate that the adiponectin receptor agonist AdipoRon inhibits pancreatic tumor growth and proliferation, thereby supporting its role as a potential therapeutic agent in pancreatic cancer.

\section{MATERIALS AND METHODS}

\section{Cell lines and culture}

MiaPaca2 and Panc1 cell lines were purchased directly from ATCC and passaged less than six months. The Panc02 cell line was acquired from the $\mathrm{NIH}$ repository. The following cell lines were kindly donated: P-4313 (Kras ${ }^{\mathrm{G} 12 \mathrm{D} /+}$ ) cell line was obtained from Dr. Lowy (University of California, San Diego) (32); K-8484 (Kras ${ }^{\mathrm{G} 12 \mathrm{D} /+}$; p53 ${ }^{\mathrm{R} 172 \mathrm{H} /+}$ ) cell line from Dr. Tuveson (Cambridge Research Institute, Cancer Research UK) (30). Cell lines are routinely authenticated by microscopic analysis and all tested clean of mycoplasma. Human cells were authenticated via STR profiling from IDEXX BioResearch (Westbrook, Maine 04092, USA) and mouse cell lines were verified for expression of KRasG12D and lack of $\alpha$ SMA. MiaPaca2, Panc1, Panc02 and K-8484 cell lines were maintained in vitro with of $10 \%$ fetal bovine serum (Omega Scientific Inc., FB-12) and 1x anti-anti (Gibco, 15240-062) in Dulbecco's Modified Eagle Media (Corning Cellgro, 10-014-CV). The P-4313 cell line was maintained in RPMI Medium 1640 (Gibco, A10491-01) supplemented with 10\% FBS, 1x Anti-anti, 1x Vitamins (Gibco, 11120-052) and 1x NEAA (Gibco, 11140-050). All cells were maintained at $37^{\circ} \mathrm{C}$ and $5 \% \mathrm{CO}_{2}$. AdipoRon was purchased from Enzo Life Science (ENZ-CHM101). Recombinant globular adiponectin (1688-AC or 1119AC), full length adiponectin (1065-AP or 5095-AC), and Leptin (Mouse 498-OB or human 398-LP) from R\&D System was used for in vitro analysis.

\section{Animal studies}

All experimental procedures using laboratory animals were approved by the animal care committee of Vanderbilt University and University of Miami. Wildtype (000664) and Adiponectin deficient (008195) mice were obtained from Jackson laboratories. Orthotopic pancreatic tumors were generated by surgically isolating the pancreas and implanting tumor cells directly into the tail of the pancreas in two month old mice. Pancreatic cancer cell lines P-4313 and K-8484 cells were trypsinized from cultures and counted on a Bio-Rad TC20. 2.5 million cells were resuspended in pharmaceutical grade phosphate buffered saline. $30 \mu \mathrm{l}$ of cell suspension was injected into the tail of the pancreas using a 27 gauge syringe. For AdipoRon treatment studies, P-4313 tumors and K-8484 were allowed to grow for 14 days and then animals were administered vehicle or AdipoRon $(5 \mathrm{mg} / \mathrm{kg} /$ day) for two weeks. At the end of each study, mice body weight was measured and then the pancreas was removed, weighed, and processed for histological and molecular analysis.

\section{Immunofluorescence}

Murine pancreatic cancer tissues were obtained from 4-6 week old PKT (Ptfla ${ }^{\text {cre/+}}$; Kras ${ }^{\mathrm{G} 12 \mathrm{D} /+}$; Tgfbr2 ${ }^{\mathrm{f} / \mathrm{fl}}$ ) mice and normal pancreas tissue was obtained from littermate mice control, not expressing Cre. Both male and female mice were used for these studies. Pancreas tissue was resected, fixed in buffered formalin overnight, and then paraffin embedded. De-identified human normal tissue samples were obtained from Vanderbilt Translational Pathology Shared Resource. Tissue microarrays of human normal and pancreatic cancer samples were obtained from BioMax (PA483c). Antigen retrieval was performed with Proteinase K (for ADIPOR2) or Citric Buffer (for ADIPOR1). Sections were washed and then endogenous peroxidases quenched with $3 \%$ peroxide in TBS before blocking ( $5 \%$ normal donkey serum, 1\% BSA, $0.1 \mathrm{M}$ $\mathrm{MgCl} 2,0.5 \%$ Tween 20, and 10mM Tris pH 7.4). Sections were stained with antibodies to ADIPOR1 (ThermoFisher Scientific, PA1-059), ADIPOR2 (ThermoFisher Scientific, PA1-1071) overnight at $4^{\circ} \mathrm{C}$. For detection, sections were labeled with appropriate species specific secondary antibody Alexa Fluor 594 and Alexa Fluor 488 (Life Technologies). Slides for co-staining were incubated for 30min at room temperature in Rhodamine Peanut Agglutinin (PNA; Vector labs RL-1072). Slides were additionally counterstained with Dapi or NucBlue Fixed Cell Stain (Molecular Probes, R37606) and mounted with Permount (Fisher Scientific, SP15-100). Slides were then scanned on a Zeiss Apotome at the Sylvester Cancer Center Analytic Imaging Core Facility. Multiple fields for multiple samples were acquired and normalized to background IgG levels. Specifically, 5 normal mouse pancreatic tissue, 5 mouse pancreatic adenocarcinoma tissue samples and 3 normal pancreatic tissue samples were evaluated, 6 field per sample were acquired and analyzed. One field per sample was acquired and analyzed on TMA with 8 human normal pancreas together with 40 human pancreatic adenocarcinoma samples. Single channel grey scale images were analyzed with ImageJ software to evaluate the mean of fluorescence as a result of integrated fluorescence intensity per area field. 


\section{Immunohistochemistry}

Vehicle or AdipoRon treated orthotopic P-4313 and K-8484 pancreatic tumors were resected from C57bl/6J mice, fixed in buffered formalin overnight, and then paraffin embedded. $6 \mu \mathrm{m}$ sections were dewaxed and rehydrated through a decreasing percentage of ethanols. Heat-induced antigen retrieval for Ki67 was performed in $10 \mathrm{mM}$ sodium citrate buffer $\mathrm{pH}$ 6.0. Sections were washed and then endogenous peroxidases quenched with $3 \%$ peroxide in TBS before blocking (5\% normal donkey serum, $1 \% \mathrm{BSA}, 0.1 \mathrm{M} \mathrm{MgCl}, 0.5 \%$ Tween 20 , and $10 \mathrm{mM}$ Tris $\mathrm{pH} 7.4)$. Sections were stained with antibodies to Ki-67 (ab15580) overnight at $4^{\circ} \mathrm{C}$. For detection, sections were labeled with appropriate species specific biotinylated secondary antibody (Vector Labs, Burlingane, CA), processed with a Vectastain kit (Vector Labs) and developed in chromogen solution (0.1 M Tris- $\mathrm{HCl} \mathrm{pH} 7.4,1.125 \mathrm{mM}$ diaminobenzidine, $0.01 \% \mathrm{H} 2 \mathrm{O} 2$ ), counterstained with Mayer's Hematoxylin Solution (Sigma), dehydrated with graded ethanols and mounted with Permount. Slides were then scanned on a Leica SCN400 Slide Scanner at the Vanderbilt Digital Histology Shared Resource. Ki67 was measured by averaging the level of staining per area of tumor from three different sections of each tumor. A total of three tumors for each treatment group were then analyzed using GraphPad Prism6. Pathological examination and staining assessment of tissue sections were verified microscopically.

\section{Reverse transcription and quantitative real-time PCR (qRT-PCR)}

Total RNA was isolated from cultured cells and tissue samples using Qiazol (Qiagen, 79306) and chloroform extraction. The aqueous layer was then purified using RNeasy kit (Qiagen, 74104). The cDNA was generated from $1 \mu \mathrm{g}$ of total RNA via reverse transcription using High Capacity cDNA kit (Applied Biosystems, 4368814). Real-time PCR analysis was carried out following the iQ SYBR green supermix (Bio-Rad, 1708882) on a CFX96 real time PCR detection system (Bio-Rad) using Qiagen QuantiTect transcript specific primers for mouse or human ADIPOR1 (QT00154217, QT00002352), ADIPOR2 (QT00165326, QT00058716) and ADIPOQ (QT01048047, QT00014091). Each sample was run in triplicate and fold-change was evaluated relative to normal samples and determined using GAPDH levels as a reference.

\section{Western blot analysis}

For the assessment of STAT3, AMPK, or ACC level and phosphorylation status, total cell protein extracts were obtained from human and mouse PDAC cell lines, as well as from mouse tissue samples, via lysis and sonication in RIPA buffer (Cell Signaling, 9806). Total cell lysates were resolved by a 7.5\% SDS-PAGE and probed with phospho-STAT3 (Cell Signaling, 9145S), phospho-AMPK (Cell Signaling, 2535S), phospho-ACC (Cell Signaling, 11818T), total STAT3 (Cell Signaling, 9139S) total AMPK (Cell Signaling, 5832S), and total ACC (Cell Signaling, 3676T). To determine equal loading, control membranes were probed with $\beta$-actin (Abgent, AM1829B). Quantitation of protein relative amounts of triplicate experiments were analyzed by ImageJ software as a ratio of each phospho protein band relative to the correspondent lane total protein band, followed by ratio to the lane's loading control.

\section{EdU incorporation assay}

Cells were dissociated with trypsin and counted

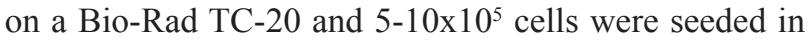
each well of a 24 well plate and allowed to adhere in full media overnight. The next day, media was replaced with treatment media consisting of DMEM supplemented with $2.5 \% \mathrm{FBS}$ and either DMSO, globular adiponectin $(1 \mu \mathrm{g} /$ $\mathrm{ml})$, full length adiponectin $(10 \mu \mathrm{g} / \mathrm{mL})$, or AdipoRon $(0.25-50 \mu \mathrm{M})$ and allowed to grow for an additional $48 \mathrm{~h}$. EdU was then added to a final concentration of $10 \mu \mathrm{M}$ and incubated for 3 to 6 hours. Cells were lightly trypsinized and released with PEB (phosphate buffer $\mathrm{pH} 7.2,2 \mathrm{mM}$ EDTA, and 1\% BSA). Cells were filtered through $30 \mu \mathrm{m}$ filter and pelleted at 350xG. Cells were then fixed overnight at $4{ }^{\circ} \mathrm{C}$ with $3 \%$ buffered formalin and subsequently permeabilized by addition of Triton $(0.5 \%)$ for 10min. Cells were pelleted and washed with phosphate buffer and 1\% BSA and then resuspended in labeling mix $(150 \mathrm{mM}$ Tris $\mathrm{pH} 8.5,1.5 \mathrm{mM}$ CuSO4, $2 \mu \mathrm{M}$ fluorAzide dye). $100 \mathrm{mM}$ ascorbic acid was added to catalyze the reaction for 20min in the dark. A five-fold excess of PEB was added and the cells were pelleted at $350 \mathrm{xG}$. Cells were then labeled with propidium iodide $(0.5 \mu \mathrm{g} /$ $\mathrm{mL}$ ) and assessed using a flow cytometer (CytoFLEX Flow Cytometer, Beckman Coulter, Inc.). Flow cytometry was performed with gating by side and forward scatter, eliminating cell doublets, then gating for propidium iodide positive cells. The percentage of EdU positive cells was gated from the total number of propidium iodide positive cells.

\section{Cell apoptosis assay}

Cells were dissociated with trypsin, counted, and 100,000 Cells were seeded in each well of a 24 well plate and allowed to adhere in full media overnight. The next day, media was replaced with treatment media consisting of DMEM supplemented with 2.5\% FBS and 
either DMSO or AdipoRon $(50 \mu \mathrm{M})$ and incubated for an additional 24h. Annexin V staining was performed following the manufacturer's protocol (Life Technologies, V13241). Cells were assessed by flow cytometry comparing propidium iodide versus Annexin V positive cells.

\section{Colony formation assay}

Pancreatic cancer cell lines were plated in triplicate for each treatment at a density of 5000 cells per well in a 6 well plate and allowed to adhere in complete media overnight. The day after, media was replaced with treatment media consisting of DMEM supplemented with $2.5 \%$ FBS and either DMSO or AdipoRon (0.25$50 \mu \mathrm{M})$. The incubation time for colony formation was 2 weeks for all cell lines following previously established protocols [48]. At the end of the treatment the media was gently removed from each of the wells by aspiration and cellular staining was performed for 20 minutes at room temperature with a solution of crystal violet $(0.05 \% \mathrm{~W} / \mathrm{v}$ crystal violet, 1\% Formaldehyde, 1x PBS, 1\% Methanol in $\mathrm{dH}_{2} \mathrm{O}$ ). The excess crystal violet was washed with $\mathrm{dH}_{2} \mathrm{O}$ and the plates were allowed to dry at room temperature. Qualitative digital images of the colonies were scanned and analyzed. Elution of the crystal violet was performed using a $10 \%$ acetic acid solution for 15 minutes at room temperature. Eluates were diluted 1:4 in $\mathrm{dH} 2 \mathrm{O}$ and the absorbance was read, in triplicate, at $590 \mathrm{~nm}$.

\section{Soft agar assay}

A 1.6\% Agar Solution (Sea Plaque Agarose, Lonza, 50101) was prepared in $\mathrm{dH}_{2} \mathrm{O}$ and autoclaved at $121^{\circ} \mathrm{C}$ for 15 minutes. The solution was kept at $56^{\circ} \mathrm{C}$ to avoid solidification. 2x RPMI solution was prepared by adding $10.3 \mathrm{~g}$ of RPMI-1640 powder (Sigma, R7755) in $500 \mathrm{ml}$ of sterile $\mathrm{dH}_{2} \mathrm{O}$, followed by the addition of $2.5 \%$ Fetal Bovine Serum, 1x L-Glutamine (Gibco, 25030-081) and $0.2 \%$ sodium bicarbonate (Gibco, 25080-094). For the bottom assay layer, 1.6\% Agar Solution was mixed with the RPMI $2 x$ solution at 1:1 ratio and $500 \mu 1$ per well was used to coat 24 well plates. Plates were then left at room temperature for 30 minutes to solidify. Pancreatic cancer cell lines were trypsinized and counted. 5000 cells per well were resuspended in 2x RPMI solution, 1.6\% agar solution was added at 1:1 ratio, and then cells were plate, in triplicate for each treatment atop the previously established bottom layer. Plates were left at room temperature for 30 minutes to solidify. Cells were then incubated in a humidified $5 \% \mathrm{CO}_{2}$ environment at $37^{\circ} \mathrm{C}$ for 2 weeks. At the endpoint, qualitative digital images of the colonies were taken and quantification for area and diameters of colonies for at least 15 fields were measured using ImageJ software.

\section{Mouse adiponectin enzyme-linked immunosorbent assay (ELISA)}

The level of adiponectin from mouse cell line condition media or mouse serum samples (1:4000 dilution) was detected using a mouse Adiponectin/Arcp 30 DuoSet ELISA Kit (R\&D System, DY1119) and analyzed using a FLUORstar OPTIMA microplate reader (BMG Labtech) according to the manufacturer's protocols.

\section{Statistical analysis}

Results are expressed as mean \pm SEM. Group results were compared by One-Way Anova or Two-Way Anova with multiple comparison or unpaired t-test when appropriate. $\mathrm{P}$ value $<0.05$ was considered significant.

\section{Abbreviations}

ADIPOR1, Adiponectin receptor 1, ADIPOR2, Adiponectin receptor 2, ADN, ADIPOQ, Adiponectin, APPL1, Adapter protein with PH domain and PTB domain and Leucine zipper, AMPK, AMP-activated protein kinase, AKT, Ak strain transforming, MAPK, mitogen-activated protein kinase, STAT3, signal transducer and activator of transcription 3, EdU, 5-ethynyl-2'-deoxyuridine

\section{Authors' contributions}

MNV conceived the study; FM, AMM, NBM, and MNV developed the methodology; FM, AMM, JC, and MNV acquired the data; FM, AMM, JC, NN, NBM, $\mathrm{LG}$, and MNV analyzed and interpreted the data; all authors contributed to the preparation and writing of the manuscript.

\section{ACKNOWLEDGMENTS}

The authors would like to acknowledge Dr. Joe Roland (Vanderbilt University) and the epithelial biology core for use of the Ariol scanner. The P-4313 cell line was provided by Dr. Lowy (University of California, San Diego). The K-8484 cell lines were provided by Dr. Tuveson (Cancer Research UK). Tissues provided by the Vanderbilt Translational Pathology Shared Resource.

\section{CONFLICTS OF INTEREST}

The authors have no conflicts of interest to declare.

\section{FUNDING}

Research was supported by the 2010 Pancreatic Cancer Action Network-AACR Career Development Award, Grant Number 10-20-25-VANS and supported by grant \#IRG 98-277-13 from the American Cancer Society. 
Supported by the University of Miami, Miller School of Medicine- Sylvester Comprehensive Cancer Center. NIH \#5U01CA143072 supported LG and AMM, NIH CA161976 supported NM and NIH CA209536 supported NN. Core services were provided through Cancer Center Support Grant 5P30 CA068485 and NIH DDRC P30DK058404.

\section{REFERENCES}

1. Rahib L, Smith BD, Aizenberg R, Rosenzweig AB, Fleshman JM, Matrisian LM. Projecting cancer incidence and deaths to 2030: the unexpected burden of thyroid, liver, and pancreas cancers in the United States. Cancer Res. 2014; 74:2913-2921.

2. Matrisian LM, Berlin JD. The Past, Present, and Future of Pancreatic Cancer Clinical Trials. American Society of Clinical Oncology educational book / ASCO American Society of Clinical Oncology Meeting. 2016; 35:e205-215.

3. Becker AE, Hernandez YG, Frucht H, Lucas AL. Pancreatic ductal adenocarcinoma: risk factors, screening, and early detection. World J Gastroenterol. 2014; 20:11182-11198.

4. McWilliams RR, Maisonneuve P, Bamlet WR, Petersen GM, Li D, Risch HA, Yu H, Fontham ET, Luckett B, Bosetti C, Negri E, La Vecchia C, Talamini R, et al. Risk Factors for Early-Onset and Very-Early-Onset Pancreatic Adenocarcinoma: A Pancreatic Cancer Case-Control Consortium (PanC4) Analysis. Pancreas. 2016; 45:311-316.

5. Chari ST, Leibson CL, Rabe KG, Ransom J, de Andrade M, Petersen GM. Probability of pancreatic cancer following diabetes: a population-based study. Gastroenterology. 2005; 129:504-511.

6. Aune D, Greenwood DC, Chan DS, Vieira R, Vieira AR, Navarro Rosenblatt DA, Cade JE, Burley VJ, Norat T. Body mass index, abdominal fatness and pancreatic cancer risk: a systematic review and non-linear dose-response meta-analysis of prospective studies. Ann Oncol. 2012; 23:843-852

7. Preziosi G, Oben JA, Fusai G. Obesity and pancreatic cancer. Surgical oncology. 2014; 23:61-71.

8. Guerra C, Schuhmacher AJ, Canamero M, Grippo PJ, Verdaguer L, Perez-Gallego L, Dubus P, Sandgren EP, Barbacid M. Chronic pancreatitis is essential for induction of pancreatic ductal adenocarcinoma by K-Ras oncogenes in adult mice. Cancer Cell. 2007; 11:291-302.

9. Paz-Filho G, Lim EL, Wong ML, Licinio J. Associations between adipokines and obesity-related cancer. Frontiers in bioscience. 2011; 16:1634-1650.

10. VanSaun MN. Molecular pathways: adiponectin and leptin signaling in cancer. Clin Cancer Res. 2013; 19:1926-1932.

11. Saxena NK, Sharma D, Ding X, Lin S, Marra F, Merlin D, Anania FA. Concomitant activation of the JAK/ STAT, PI3K/AKT, and ERK signaling is involved in leptin-mediated promotion of invasion and migration of hepatocellular carcinoma cells. Cancer Res. 2007; 67:2497-2507.

12. Saxena NK, Taliaferro-Smith L, Knight BB, Merlin D, Anania FA, O'Regan RM, Sharma D. Bidirectional crosstalk between leptin and insulin-like growth factor-I signaling promotes invasion and migration of breast cancer cells via transactivation of epidermal growth factor receptor. Cancer Res. 2008; 68:9712-9722.

13. Mendonsa AM, Chalfant MC, Gorden LD, VanSaun MN. Modulation of the Leptin Receptor Mediates Tumor Growth and Migration of Pancreatic Cancer Cells. PLoS One. 2015; 10:e0126686.

14. Wang Y, Lam JB, Lam KS, Liu J, Lam MC, Hoo RL, Wu D, Cooper GJ, Xu A. Adiponectin modulates the glycogen synthase kinase-3beta/beta-catenin signaling pathway and attenuates mammary tumorigenesis of MDA-MB-231 cells in nude mice. Cancer Res. 2006; 66:11462-11470.

15. Korner A, Pazaitou-Panayiotou K, Kelesidis T, Kelesidis I, Williams CJ, Kaprara A, Bullen J, Neuwirth A, Tseleni S, Mitsiades N, Kiess W, Mantzoros CS. Total and highmolecular-weight adiponectin in breast cancer: in vitro and in vivo studies. J Clin Endocrinol Metab. 2007; 92:1041-1048

16. Adachi M, Brenner DA. High molecular weight adiponectin inhibits proliferation of hepatic stellate cells via activation of adenosine monophosphate-activated protein kinase. Hepatology. 2008; 47:677-685.

17. Bub JD, Miyazaki T, Iwamoto Y. Adiponectin as a growth inhibitor in prostate cancer cells. Biochem Biophys Res Commun. 2006; 340:1158-1166.

18. Beales IL, Garcia-Morales C, Ogunwobi OO, Mutungi G. Adiponectin inhibits leptin-induced oncogenic signalling in oesophageal cancer cells by activation of PTP1B. Molecular and cellular endocrinology. 2014; 382:150-158.

19. Miyazaki T, Bub JD, Uzuki M, Iwamoto Y. Adiponectin activates c-Jun NH2-terminal kinase and inhibits signal transducer and activator of transcription 3. Biochem Biophys Res Commun. 2005; 333:79-87.

20. Zhang J, Hochwald SN. Plasma adiponectin: a possible link between fat metabolism and pancreatic cancer risk. Journal of the National Cancer Institute. 2013; 105:79-80

21. Bao Y, Giovannucci EL, Kraft P, Stampfer MJ, Ogino S, Ma J, Buring JE, Sesso HD, Lee IM, Gaziano JM, Rifai N, Pollak MN, Cochrane BB, et al. A prospective study of plasma adiponectin and pancreatic cancer risk in five US cohorts. Journal of the National Cancer Institute. 2013; 105:95-103.

22. Shin E, Yu YD, Kim DS, Won NH. Adiponectin receptor expression predicts favorable prognosis in cases of hepatocellular carcinoma. Pathology oncology research. 2014; 20:667-675. 
23. Byeon JS, Jeong JY, Kim MJ, Lee SM, Nam WH, Myung SJ, Kim JG, Yang SK, Kim JH, Suh DJ. Adiponectin and adiponectin receptor in relation to colorectal cancer progression. Int J Cancer. 2010; 127:2758-2767.

24. Dalamaga M, Migdalis I, Fargnoli JL, Papadavid E, Bloom E, Mitsiades N, Karmaniolas K, Pelecanos N, TseleniBalafouta S, Dionyssiou-Asteriou A, Mantzoros CS. Pancreatic cancer expresses adiponectin receptors and is associated with hypoleptinemia and hyperadiponectinemia: a case-control study. Cancer Causes Control. 2009; 20:625-633.

25. Pajvani UB, Du X, Combs TP, Berg AH, Rajala MW, Schulthess T, Engel J, Brownlee M, Scherer PE. Structurefunction studies of the adipocyte-secreted hormone Acrp30/ adiponectin. Implications fpr metabolic regulation and bioactivity. J Biol Chem. 2003; 278:9073-9085.

26. Kadowaki T, Yamauchi T, Kubota N. The physiological and pathophysiological role of adiponectin and adiponectin receptors in the peripheral tissues and CNS. FEBS Lett. 2008; 582:74-80.

27. Kadowaki T, Yamauchi T. Adiponectin and adiponectin receptors. Endocr Rev. 2005; 26:439-451.

28. Fruebis J, Tsao TS, Javorschi S, Ebbets-Reed D, Erickson MR, Yen FT, Bihain BE, Lodish HF. Proteolytic cleavage product of $30-\mathrm{kDa}$ adipocyte complement-related protein increases fatty acid oxidation in muscle and causes weight loss in mice. Proc Natl Acad Sci U S A. 2001; 98:2005-2010.

29. Okada-Iwabu M, Yamauchi T, Iwabu M, Honma T, Hamagami K, Matsuda K, Yamaguchi M, Tanabe H, Kimura-Someya T, Shirouzu M, Ogata H, Tokuyama $\mathrm{K}$, Ueki $\mathrm{K}$, et al. A small-molecule AdipoR agonist for type 2 diabetes and short life in obesity. Nature. 2013; 503:493-499.

30. Deepa SS, Dong LQ. APPL1: role in adiponectin signaling and beyond. Am J Physiol Endocrinol Metab. 2009; 296:E22-36.

31. Schapira DV. Diet, obesity, fat distribution and cancer in women. Journal of the American Medical Women's Association. 1991; 46:126-130.

32. Inadera $H$. The usefulness of circulating adipokine levels for the assessment of obesity-related health problems. Int J Med Sci. 2008; 5:248-262.

33. de Luis DA, Gonzalez Sagrado M, Conde R, Aller R, Izaola O, Castro MJ. Circulating adipocytokines in morbid obese patients, relation with cardiovascular risk factors and anthropometric parameters. Nutr Hosp. 2011; 26:91-96.

34. Trayhurn P, Wood IS. Adipokines: inflammation and the pleiotropic role of white adipose tissue. Br J Nutr. 2004; 92:347-355.

35. Hopkins BD, Goncalves MD, Cantley LC. Obesity and Cancer Mechanisms: Cancer Metabolism. Journal of clinical oncology. 2016; 34:4277-4283.
36. Yamauchi N, Takazawa Y, Maeda D, Hibiya T, Tanaka M, Iwabu M, Okada-Iwabu M, Yamauchi T, Kadowaki T, Fukayama M. Expression levels of adiponectin receptors are decreased in human endometrial adenocarcinoma tissues. International journal of gynecological pathology. 2012; 31:352-357.

37. Ayyildiz T, Dolar E, Ugras N, Adim SB, Yerci O. Association of adiponectin receptor (Adipo-R1/-R2) expression and colorectal cancer. Asian Pac J Cancer Prev. 2014; 15:9385-9390.

38. Kim AY, Park YJ, Pan X, Shin KC, Kwak SH, Bassas AF, Sallam RM, Park KS, Alfadda AA, Xu A, Kim JB. Obesityinduced DNA hypermethylation of the adiponectin gene mediates insulin resistance. Nature communications. 2015; 6:7585.

39. Ishikawa M, Kitayama J, Yamauchi T, Kadowaki T, Maki T, Miyato H, Yamashita H, Nagawa H. Adiponectin inhibits the growth and peritoneal metastasis of gastric cancer through its specific membrane receptors AdipoR1 and AdipoR2. Cancer science. 2007; 98:1120-1127.

40. Kim AY, Lee YS, Kim KH, Lee JH, Lee HK, Jang SH, Kim SE, Lee GY, Lee JW, Jung SA, Chung HY, Jeong S, Kim JB. Adiponectin represses colon cancer cell proliferation via AdipoR1- and -R2-mediated AMPK activation. Mol Endocrinol. 2010; 24:1441-1452.

41. Sharma D, Wang J, Fu PP, Sharma S, Nagalingam A, Mells J, Handy J, Page AJ, Cohen C, Anania FA, Saxena NK. Adiponectin antagonizes the oncogenic actions of leptin in hepatocellular carcinogenesis. Hepatology. 2010; 52:1713-1722.

42. Kato M, Watabe K, Tsujii M, Funahashi T, Shimomura I, Takehara T. Adiponectin inhibits murine pancreatic cancer growth. Dig Dis Sci. 2014; 59:1192-1196.

43. Huang B, Cheng X, Wang D, Peng M, Xue Z, Da Y, Zhang N, Yao Z, Li M, Xu A, Zhang R. Adiponectin promotes pancreatic cancer progression by inhibiting apoptosis via the activation of AMPK/Sirt1/PGC-1alpha signaling. Oncotarget. 2014; 5:4732-4745. https://doi.org/10.18632/ oncotarget.1963.

44. Nagathihalli NS, Castellanos JA, Shi C, Beesetty Y, Reyzer ML, Caprioli R, Chen X, Walsh AJ, Skala MC, Moses HL, Merchant NB. Signal Transducer and Activator of Transcription 3, Mediated Remodeling of the Tumor Microenvironment Results in Enhanced Tumor Drug Delivery in a Mouse Model of Pancreatic Cancer. Gastroenterology. 2015; 149:1932-1943 e1939.

45. Scholz A, Heinze S, Detjen KM, Peters M, Welzel M, Hauff P, Schirner M, Wiedenmann B, Rosewicz S. Activated signal transducer and activator of transcription 3 (STAT3) supports the malignant phenotype of human pancreatic cancer. Gastroenterology. 2003; 125:891-905.

46. Nagaraj NS, Washington MK, Merchant NB. Combined blockade of Src kinase and epidermal growth factor receptor with gemcitabine overcomes STAT3-mediated resistance 
of inhibition of pancreatic tumor growth. Clin Cancer Res. 2011; 17:483-493.

47. Nagathihalli NS, Castellanos JA, VanSaun MN, Dai $\mathrm{X}$, Ambrose $\mathrm{M}$, Guo Q, Xiong $\mathrm{Y}$, Merchant NB. Pancreatic stellate cell secreted IL-6 stimulates STAT3 dependent invasiveness of pancreatic intraepithelial neoplasia and cancer cells. Oncotarget. 2016; 7:6598265992. https://doi.org/10.18632/oncotarget.11786.
48. Peng DF, Hu TL, Schneider BG, Chen Z, Xu ZK, El-Rifai W. Silencing of glutathione peroxidase 3 through DNA hypermethylation is associated with lymph node metastasis in gastric carcinomas. PLoS One. 2012; 7:e46214. 